\title{
As Inteligências Múltiplas: Uma Análise de Conteúdo de Pesquisa
}

\section{Resumo}

Este artigo trata de uma análise dos aspectos cognitivos do pesquisador, a partir da teoria das inteligências múltiplas. $\mathrm{Na}$ teoria das inteligências múltiplas (IM) o conceito de inteligência é compreendida como uma capacidade geral, encontrada em graus variáveis em todos os indivíduos e implica na capacidade de resolver problemas ou elaborar produtos que são importantes em determinado ambiente ou comunidade cultural. Os diversos tipos de inteligências estão localizados em áreas distintas do cérebro e podem funcionar de modo independente ou em conjunto estas inteligências podem definir a espécie humana. Embora estas inteligências sejam até certo ponto independentes uma das outras, elas raramente funcionam isoladamente. Faz-se necessário o pesquisador ser um profissional com ampla visão e conhecimento da vida, seus aspectos cognitivos precisam ir além de um raciocínio lógico, que compreenda o ser humano os sentimentos, valores, crenças, e que administre bem suas emoções, buscando o autoconhecimento, além de ser sensível que tenha habilidade para enfrentar as mais profundas as questões humanas

Palavras-chave: Inteligências múltiplas; Pesquisador; Aspectos cognitivos

\section{Abstract}

This article is an analysis of the cognitive aspects of the researcher, from the theory of multiple intelligences. In the theory of multiple intelligences the concept of intelligence is understood as a general ability found in varying degrees in all subjects and implies the ability to solve problems or develop products that are important in a particular environment or cultural community. The various types of intelligences are located in separate areas of the brain and may act independently or together these intelligences may define the human species. Although these intelligences are somewhat independent of one another, they rarely work in isolation. If the researcher is required to be a professional with broad vision and knowledge of life, where their cognitive aspects goes beyond logical reasoning, which includes the human feelings, values, beliefs, and manage their emotions well, seeking selfknowledge besides being sensitive that has the ability to cope with the deeper human issues.

Keywords: Multiple intelligences; researcher, cognitive aspects

\footnotetext{
1 Mauro Maia Laruccia - Professor Dr. Da Faculdade de Economia e Administração PUC/SP e Prof. Pesquisador do Grupo de Pesquisa e Iniciação Científica, Orientador da Oficina de Artigos das Faculdades Integradas Campos Salles. Rua Nossa Senhora da Lapa, 284, São Paulo 05072-000, Brasil. E-mail: mauro.laruccia@gmail.com

2 Sergio Roberto Cosmano - Fundação Jorge Duprat Figueiredo de Segurança e Medicina do Trabalho. Rua Capote Valente, 710, São Paulo 05409-002, Brasil. E-mail: sergio.cosmano@fundacentro.gov.br
} 


\section{Apresentação}

O presente artigo trata-se de uma reflexão a respeito de aspectos cognitivos da atividade de pesquisa, mais especificamente do pesquisador, a partir da teoria das inteligências múltiplas. A inquietação a respeito do tema resultou da discussão em sala de aula a respeito das inteligências relacionadas às diferentes atividades profissionais. Nessa discussão ao ser nomeada a atividade profissional cada aluno propunha uma das inteligências, mas ao falarmos do pesquisador a resposta foi unanime lógico-matemática.

Realmente a atividade de pesquisa exige uma lógica e uma organização presentes nessa inteligência, mas ao nos depararmos com um problema de pesquisa social, temos que nos preocupar com aspectos que muitas vezes passariam sem destaque para uma atuação lógica e dita racional. Essa forma de encararmos a ciência nos é um legado do racionalismo, do método positivista de Comte, e da visão cartesiana da ciência. A divisão, ou melhor, segregação da razão e emoção, em que a segunda não era valorizada nem reconhecida como elementos importante da construção do conhecimento.

Essa visão epistemológica fez com que durante séculos a ciência, portanto, todas as teorias anulassem este elemento. Esta reflexão é perpassada por questões da história e filosofia da ciência. Destacamos algumas contribuições da teoria das Inteligências Múltiplas: o repensar do conceito de inteligência, mudança do paradigma da inteligência e da aprendizagem, reconhecimentos das diferentes individuais, consolidação de um pensar a respeito da complementariedade ao falarmos de inteligência e a complexidade dos aspectos cognitivos e cognoscitivos.

\section{2. $O$ conceito de inteligência}

A "inteligência" é uma capacidade geral, encontrada em graus variáveis em todos os indivíduos. Ela é a forma como o indivíduo consegue resolver problemas. (GARDNER, 2000). A questão da definição de inteligência é central em nossa investigação, na verdade é na definição de inteligência que a teoria das inteligências múltiplas diverge dos pontos de vista tradicionais. Segundo Gardner (2000) numa visão tradicional a inteligência é definida operacionalmente como a capacidade de responder a itens em testes de inteligência. A influência, a partir dos resultados dos testes, de alguma capacidade, de alguma capacidade subjacente é apoiada por técnicas estatísticas que comparam respostas de sujeitos em diferentes idades, a aparente correlação desses resultados de testes através das idades corrobora a noção de que a faculdade geral da inteligência, não muda muito com a idade ou com o treinamento ou experiência, ela é um atributo ou faculdade inata do individuo.

Ainda para este autor, a teoria das inteligências múltiplas, por outro lado, pluraliza o conceito tradicional. Uma inteligência implica na capacidade de resolver problemas ou elaborar produtos que são importantes em determinado ambiente ou comunidade cultural. A teoria das inteligências múltiplas é elaborada à luz das origens biológicas de cada capacidade de resolver problemas, destacam-se as capacidades que são universais na espécie humana. Cada inteligência deve ter uma operação ou um conjunto de operações identificáveis. Como um sistema computacional com base neural, cada inteligência é ativada ou "desencadeada" por certos tipos de informação interna ou externamente apresentados. Uma inteligência também deve ser capaz de ser codificada num sistema de símbolos, um sistema de significados culturalmente criado, que captura e transmite formas importantes de informação. A linguagem, a pintura e a matemática são 
apenas três sistemas de símbolos quase universais, necessários a sobrevivência e produtividade humana. Embora seja possível que a inteligência prossiga sem um sistema simbólico concomitante, uma característica primaria da inteligência humana provavelmente é a sua gravitação rumo a essa incorporação.

Segundo Gardner os seres humanos dispõem de graus variados e inteligências e maneiras diferentes, com elas se combinam, organizam e se utilizam dessas capacidades intelectuais, para resolver problemas e criar produtos, embora estas inteligências sejam até certo ponto independentes uma das outras, elas raramente funcionam isoladamente.

A Teoria das Inteligências Múltiplas resulta de anos de investigação para se conhecer as capacidades cognitivas e cognoscitivas do homem, constituindo-se em uma nova concepção científica sobre a mente, uma visão pluralista, que reconhece diferentes facetas de cognição. Todo ser humano excluindo-se os casos de lesões cerebrais, possui capacidades a serem desenvolvidas, quais sejam, as inteligências: lógico-matemática, espacial, linguística, interpessoal, intrapessoal, musical, corporal cenestésica (1993) com o possível acréscimo das inteligências naturalista, espiritual e existencial (2001)

Ao pensarmos na atividade científica nos deteremos na reflexão sobre seu contexto, os problemas científicos surgem do e no cotidiano fazendo-se necessário realizar inúmeras construções para podermos detectar os vários aspectos da vida social cotidiana, pois o cotidiano é a vida do homem, como aponta Heller (2008). Esse cotidiano precisa ser conhecido e reconhecido em sua complexidade e plurifatorialidade.

Muitas vezes isso exige do pesquisador uma atitude profissional com ampla visão e conhecimento da vida, isso implica aspectos para além do raciocínio lógico, faz se necessária uma compreensão do ser humano seus sentimentos, valores e crenças, para que isso seja possível é necessário que ele administre seus sentimentos e emoções, buscando o autoconhecimento, para além do visível e concreto atingindo o ser sensível e tênue. Ao trabalhar com o cotidiano e com o homem são exigidas do profissional, habilidades para enfrentar as mais profundas questões humanas e uma abertura para ver o mundo e o universo em que vive a partir de um olhar interdisciplinar e não apenas disciplinar.

Segundo Gardner os seres humanos dispõem de graus variados e inteligências e maneiras diferentes, com que elas se combinam e organizam e se utilizam dessas capacidades intelectuais, para resolver problemas e criar produtos, embora estas inteligências sejam até certo ponto independentes uma das outras, elas raramente funcionam isoladamente.

\section{Retomamos Inteligência Lógico-Matemática}

\begin{abstract}
Inteligência Lógico-Matemática: Possui a capacidade lógica e matemática, com competência mais diretamente associada ao pensamento científico, como pesquisadores, cientistas, engenheiros, etc. $\mathrm{O}$ estímulo para seu desenvolvimento estrutura na pessoa novas formas sobre o pensar de forma abstrata $\mathrm{e}$ conceitual, e uma percepção apurada dos elementos da grandeza, peso, distância, tempo e outros que envolvem ação sobre o ambiente, com habilidade para raciocínio dedutivo .
\end{abstract}

\begin{abstract}
A inteligência é um atributo ou uma faculdade inata do ser humano, Gardner procurou ampliar este conceito de inteligência, para ele, é a capacidade de solucionar problemas ou elaborar produtos que são importantes em um determinado ambiente ou comunidade cultural. A capacidade de resolver problemas permite às pessoas abordar situações, atingir objetivos e localizar caminhos adequados a esse objetivo (TRAVASSOS, 2001).
\end{abstract}

Esta capacidade de solucionar problemas ou elaborar produtos, abordar situações, atingir objetivos e localizar caminhos adequados dos mais diversos, é necessário muitas vezes que o pesquisador seja um profissional não somente racional e sim traga em seu perfil outros tipos de inteligências que será fundamental na hora de desenvolver seu projeto de pesquisa.

Segundo Gardner (2002) nos últimos séculos, sobretudo, nas sociedades ocidentais, difundiu-se um ideal, o da pessoa inteligente. As dimensões exatas deste ideal evoluem com 
o tempo e o cenário. Em escolas tradicionais, inteligente era quem dominava as línguas clássicas e a matemática, particularmente a geometria. Em um cenário empresarial, inteligente era quem previa oportunidades comerciais, assumia riscos calculados, construía uma organização, mantendo as contas equilibradas e os acionistas satisfeitos.

\section{Modelos da teoria das inteligências múltiplas}

Segundo Howard Gardner (2002) o primeiro teste de sucesso escolar foi realizado e desenvolvido pelo psicólogo Alfred Binet em 1900. Este teste tinha por finalidade diagnosticar crianças retardadas e crianças normais. Após a primeira Guerra Mundial este teste foi aplicado nos soldados com a finalidade de diagnosticar a inteligência dos soldados. Com a propagação deste teste pensou-se que era possível medir quantitativamente a inteligência.

Gardner propôs projeto zero de Harvard, iniciado por Nelson Goodman e co-dirigido por Howard Gardner e David Perkins, realiza pesquisas básicas sobre cognição, aprendizagem e artes há 30 anos. A Universidade Harvard, nos Estados Unidos, desenhou o Projeto Zero, que reúne equipes interdisciplinares com o objetivo de estudar as relações entre a inteligência, a compreensão e o ensino.

Segundo Gardner cada pessoa tem uma composição diferente de inteligência, podemos melhorar o ensino atuando nas múltiplas inteligências; estes tipos de inteligência estão localizados em áreas distintas do cérebro e podem funcionar de modo independente ou em conjunto estas inteligências podem definir a espécie humana, embora estas inteligências sejam até certo ponto independentes uma das outras, elas raramente funcionam isoladamente, todas as pessoas possuem todos os nove tipos de inteligências em graus variados. Exceto em indivíduos anormais, as inteligências sempre funcionam combinadas, e qualquer papel adulto sofisticado envolverá uma fusão de varias delas

As pessoas criativas se destacam em termos de determinadas inteligências, Einstein tinha uma inteligência lógico-matemática excepcional, mas suas capacidades espaciais eram extraordinárias mesmo entre os físicos. Freud se considerava um cientista e tinha capacidade lógico-matemática adequada, porém era mais genial na inteligência linguística, isto contribuiu para o seu imenso sucesso com o publico, mas também gerou uma tensão permanente com cientistas com formação convencional (GARDNER, 2002).

A inteligência musical de Stravinski era excelente, mas ele também se destacou em outras inteligências artísticas, e talvez isto explique porque ele foi um grande compositor de balés, era capaz de musicar um texto e tornou-se um dos comentadores artísticos mais incisivos de sua época. Os criadores excepcionais também tem fraquezas intelectuais, Freud, por exemplo, não tinha inteligência musical, enquanto Picasso foi péssimo aluno e mal dominava as primeiras letras. Mas os criadores não se deixam vencer por estas fraquezas intelectuais, aprendem a ignorá-las e a procuram ajuda na área em que são deficientes. Os indivíduos criativos acabam conhecendo seus pontos fortes e identificam seus nichos cognitivos ou culturais, que eles buscam totalmente conscientes de suas vantagens competitivas. Gardner descreve diferentes inteligências num total de nove, visto que todos os seres humanos possuem potencialidades para desenvolvê-las, quais sejam:

\subsection{Inteligência musical}

Para Gardner (2002), certas partes do cérebro desempenham papeis importantes na percepção e na produção da musica. Estas áreas estão caracteristicamente localizadas no 
hemisfério direito, embora a capacidade musical não esteja claramente "localizada" em uma área tão especifica como a linguagem. As evidencias que apoiam a interpretação da capacidade musical como a inteligência "chegam" por varias fontes. Mesmo que a capacidade musical não esteja tipicamente considerada uma capacidade intelectual, como a matemática, ele se qualifica a partir de nossos critérios. Por definição, ela merece ser considerada, e, tendo em vista os dados, na inclusão está empiricamente justificada.

\subsection{Inteligência lógico-matemática}

$\mathrm{O}$ individuo talentoso, o processo de resolução do problema geralmente é surpreendente rápido - o cientista bem sucedido lida com muitas variáveis ao mesmo tempo e cria numerosas hipóteses que são avaliadas e depois, por suas vez, aceita ou rejeita. Juntamente com a associada capacidade da linguagem, o raciocínio lógico-matemático, proporciona a principal base para os testes de QI. Certas áreas do cérebro são mais importantes do que outras no calculo matemático. Há idiotas sábios que realizam grandes façanhas de calculo, mesmo que continuem sendo tragicamente deficientes na maioria de outras áreas. As criança prodígio na matemática, existem em grande numero. $\mathrm{O}$ desenvolvimento desta inteligência nas crianças foi cuidadosamente documentado por Jean Piaget e outros psicólogos. A pessoa dotada de inteligência lógico - matemática tem habilidade de discernir padrões lógicos e numéricos, elementos da grandeza, peso, distância, tempo, é a inteligência de um cientista e pesquisador.

\subsection{Inteligência linguista}

A capacidade linguista de "inteligência" é consistente com a psicologia tradicional. A habilidade da linguagem é universal, e seu desenvolvimento nas crianças é surpreendente constante em todas as culturas. Mesmo nas populações surdas, em que uma linguagem manual de sinais não é explicitamente ensinada, as crianças, frequentemente “inventam" sua própria linguagem manual e a utilizam secretamente. Este perfil tem habilidade lida com palavras de maneira criativa, com habilidades verbais bem desenvolvidas e tem sensibilidade para os sons e significados das palavras, também é desenvolvida esta habilidade nos poetas e escritores etc.

\subsection{Inteligência espacial}

A solução de problemas espaciais é necessária na navegação e no uso do sistema motivacional de mapas. Outros tipos de problemas espaciais são convocados quando visualizamos um objeto de um ângulo diferente, e no jogo de xadrez. As artes visuais também utilizam esta inteligência no uso do espaço. Os pacientes com danos específicos nas regiões do hemisfério direito tentarão compensar suas falhas espaciais com estratégias linguistas. Elas tentarão raciocinar em voz alta, por em duvida a tarefa ou inclusive inventar respostas. Mas essas estratégias não espaciais raramente são bem sucedidas. As populações cegas ilustram a distinção entre a inteligência espacial e a percepção visual. Uma pessoa cega pode reconhecer formas através de um método indireto. Passar a mão ao longo do objeto traduz a duração do movimento que por sua vez é traduzida no formato do objeto. Para a pessoa cega, o sistema perceptivo da modalidade tátil equivale a modalidade visual na pessoa que enxergar. A analogia entre o raciocínio espacial do cego e o raciocínio linguístico do surdo é notável. 


\subsection{Inteligência interpessoal}

A inteligência interpessoal está baseada numa capacidade nuclear de perceber distinções entre os outros, em especial, contrastes em seus estados de animo, temperamentos, motivações e intenções. Em formas avançadas, esta inteligência permite que $\mathrm{o}$ adulto experiente perceba as intenções e desejos de outras pessoas, mesmo que elas os escondam. Essa capacidade aparece numa forma altamente sofisticada em lideres religioso ou políticos, professores, terapeutas e pais.

\subsection{Inteligência intrapessoal}

O conhecimento dos aspectos internos de uma pessoa: o acesso ao sentimento da própria vida, a gana das próprias emoções, a capacidade de discriminar essas emoções e eventualmente rotulá-las e utilizá-las como uma maneira de entender e orientar o próprio comportamento. A pessoa com boa inteligência intrapessoal possui um modelo viável e efetivo de si mesma. Uma vez que esta inteligência é a mais privada, ela requer a evidencia a partir da linguagem, da musica ou de alguma outra forma mais expressiva de inteligência para que o observador a perceba funcionando. A inteligência interpessoal nos permite compreender a nós mesmos e trabalhar conosco. No senso de eu dom individuo, encontramos uma fusão de componentes e intrapessoais.

\subsection{Inteligência naturalista}

As pessoas dotadas desta inteligência têm habilidade de reconhecer a natureza plantas e animais, entende o nascimento e a morte dos seres vivos no mundo.

\subsection{Inteligência existencial}

Sensibilidade e habilidade para compreender sobre as existência humana, o significado da vida e morte. Questiona com facilidade sobre a existência da vida e do mundo. Com este perfil de inteligência convivemos no dia a dia, e presenciamos nos homens em busca da religião para terem paz de espírito muitas vezes devido a amenizar os problemas, seja sentimental, espiritual ou emocional.

\section{Procedimentos metodológicos}

O estudo foi realizado usando a técnica de "análise de conteúdo". Nesta pesquisa, os estudos sobre a teoria IM (ou seja, teses de doutorado, dissertações de mestrado indexadas no Banco de Teses da Capes, bem como artigos publicados nas revistas indexadas na base de dados do Periódicos Capes foram analisados em relação às variáveis.

Os estudos que foram incluídos nesta pesquisa foi baseado em 71 teses de mestrado, 8 teses de doutorado e 18 artigos de pesquisa foram analisados segundo os seguintes 11 questões na próxima página: 
1. Qual é a distribuição de estudos IM em termos de tipo de publicação?

2. Qual é a distribuição de estudos IM em termos de seus tópicos?

3. Qual é a distribuição de estudos IM em termos do seu ano de publicação?

4. Qual é a distribuição de estudos IM em termos de sexo dos pesquisadores?

5. Qual é a distribuição de estudos IM em termos de seu projeto de pesquisa?

6. Qual é a distribuição de estudos IM em termos de metodologia de pesquisa?

7. Qual é a distribuição de estudos IM em termos dos seus técnica de análise de dados?

8. Qual é a distribuição de estudos IM em termos de tipo de amostragem?

9. Qual é o número médio de participantes de estudos IM?

10. Qual é a distribuição de artigos de IM em termos de suas revistas?

11. Qual é o número médio de autores de artigos IM?

\section{Resultados da pesquisa}

1. Tipo de publicação: dissertações de mestrado $(73,2 \%)$, teses de doutorado $(8,2 \%)$, artigos de pesquisa $(18,6 \%)$. A maioria dos estudos IM foram conduzidos em nível de mestrado.

2. Tema de pesquisa: - perfis de estudantes IM (7,2\%) - A relação entre IM e estilos de aprendizagem e estratégias $(3,1 \%)$, a relação entre IM e desempenho acadêmico $(2,1 \%)$, desenvolvimento de IM para crianças (1\%) - O IM teoria e currículo $(5,2 \%)$ - a teoria IM e orientação escolar $(2,1 \%)$ - a teoria IM e livros didáticos (3,1\%) - Percepções sobre as implementações da teoria IM (12,4\%) - O efeito da teoria IM no desempenho acadêmico e nas atitudes no jardim de infância $(2,1 \%)$ - O efeito da teoria IM em desempenho acadêmico e as atitudes dos alunos do ensino fundamental $(45,4 \%)$ - O efeito da teoria IM no do ensino médio (15,5\%) - os efeito da teoria IM na realização dos estudantes do ensino superior acadêmico e atitudes (1\%). A maioria dos estudos IM enfoca nos alunos do ensino fundamental.

3. Ano de publicação: - 1999 (2,1\%) - 2000 $(2,1 \%)-2001(5,2 \%)-2002(2,1 \%)-2003$ $(6,2 \%)-2004(6,2 \%)-2005(13,4 \%)-2006$
$(44,3 \%)-2007$ (18,6\%). A maioria dos estudos IM foram concluídas no ano de 2006.

4. Sexo dos pesquisadores: - Masculino $(39,2 \%)$ - Feminino (60,8\%). A maioria dos estudos IM têm sido conduzidos por investigadores do sexo feminino.

5. Projeto de pesquisa: - Revisão da literatura (1\%) - Modelo de desenvolvimento (2,1\%) - A análise de conteúdo $(2,1 \%)$ - Descritiva $(34,7 \%)$ - empírica $(65,3 \%)$. A maioria dos estudos IM têm sido conduzidos empiricamente.

6. Metodologia de pesquisa: - qualitativa $(12,4 \%)$ - Quantitativo (62,9\%) - Misto $(23,7 \%)$ - Outros (1\%). A maioria dos estudos IM têm utilizado a metodologia de pesquisa quantitativa.

7. Técnica de coleta de dados: - Observações $(24,7 \%)$ - entrevistas (24,7\%) - análise de documentos $(13,4 \%)$ - Levantamentos $(20,6 \%)$ - Testes $(60,8 \%)$ - Estoques $(13,4 \%)$ - Escalas (34\%) - GPA ( $2,1 \%)$ - Outros (1\%). A maioria dos estudos IM usaram testes e escalas, como procedimentos de coleta de dados.

8. Tipo de amostragem: - alunos do jardim de infância $(6,2 \%)$ - Menores alunos do ensino fundamental $(21,6 \%)$ - Alta alunos do ensino fundamental $(35,1 \%)$ - alunos do ensino secundário $(17,5 \%)$ - estudantes de ensino 
superior $(3,1 \%)$ - professores estagiários $(2,1 \%)$ - primário professores $(7,2 \%)$ - Assunto professores $(7,2 \%)$ - os administradores (1\%) Os pais $(2,1 \%)$ - Documentos $(6,2 \%)$ - outros (1\%). A maioria dos estudos IM têm sido realizados com alunos do ensino fundamental.

9. O número médio de participantes dos estudos IM: - Descritiva $(\mathrm{n}=345)$ - empírica (n =73) - Total $(\mathrm{n}=162)$. O número médio do participante estudos IM é de cerca de 162.

10. O número médio de autores da artigos IM: $\mathrm{N}=$ cerca de 2 .

\section{Considerações finais}

Este estudo mostra que os pesquisadores começaram a interessar-se na teoria IM desde sua primeira apresentação em 1983. Parece que o interesse para a teoria cada vez mais IM continuou até o ano de 2006 e novamente começou a diminuir depois de então. Entre os anos de 1999 e 2007, em média, cerca de 10-11 IM estudos têm sido publicados anualmente. Este número parece ser insuficiente para ter um quadro completo sobre a projeção da teoria IM no sistema de ensino. O estudo conclui que os estudos mais qualitativos são necessários sobre a questão do Como pode inteligências múltiplas das crianças e adultos pode ser desenvolvida?
Frente estes apontamentos é importante ressaltar o pesquisador que mesmo tendo em seu perfil sendo lógico-matemático há necessidade de explorar outras inteligências. Visto que é possível funcionar de modo independente ou em conjunto estas inteligências podendo definir melhor na atuação de pesquisador na resolução de problemas. E esta capacidade de solucionar problemas ou elaborar produtos, abordar situações, atingir objetivos e localizar caminhos adequados dos mais diversos, observamos se o pesquisador tiver além da inteligência lógico-matemática a inteligência intrapessoal e a inteligência existencial, terá a probabilidade de terem um maior sucesso em suas produções cientificas e facilidade em resolver os problemas em vários aspectos na sociedade. Muitas vezes se faz necessário o pesquisador ser um profissional com ampla visão e conhecimento da vida, onde os seus aspectos cognitivos vá além de um raciocínio lógico, compreenda o ser humano os sentimentos, valores, crenças e seu semelhante, e que administre bem seus sentimentos e emoções, buscando o autoconhecimento, além de ser sensível e tenha habilidade para enfrentar as mais profundas as questões humanas.

\section{Referências Bibliográficas}

ALMEIDA, E. Gardner e a teoria das inteligências múltiplas. [200?]. Disponível em: $<$ http:// www.lincx.com.br/lincx/saude_a_z/saude_mental/gardner.asp>. Acesso em: 24 maio 2010.

CHAPMAN, C.; FREEMAN, L. Multiple intelligences centers and projects. Heights, IL: Skylight Training and Publishing, 1996

GARDNER, H. Inteligências múltiplas: a teoria na pratica. Tradução: Maria Adriana Veríssimo Veronse. Porto Alegre: Artes médicas, 2000.

GARDNER, H. Inteligência: um conceito reformulado. Tradução: Adalgisa campos da Silva. 2 ed. Rio de Janeiro: Objetiva, 2002.

GARDNER, H. Frames of mind. New York, Basic Books Inc., 1985.

GARDNER, H. The mind's new science. New York, Basic Books Inc., 1987.

MATTOS, C. P. Um estudo da importância das inteligências múltiplas para o desenvolvimento 
do ser humano e das organizações. Itajubá: UNIFEI, 2005. (Trabalho de Conclusão de Curso apresentado ao Programa de Pós-Graduação em Engenharia de Produção da Universidade Federal de Itajubá). Itajubá, 2005.

TABACHNICK, B.; FIDELL, L. Using multivariate statistics. New York: Allyn and Bacon, 2001.

TRAVASSOS, L. C. P. Inteligências múltiplas. Revista de Biologia e Ciências da Terra. v. 1, n. 2, 2001.

VEENEMA, S.; GARDNER, H. Multimedia and multiple intelligences. The American Prospect, v.27, n. 29, 1996. 